Research Article

\title{
Does Isoniazid Preventive Therapy Provide Better Treatment Outcomes in HIV-Infected Individuals in Northern Ethiopia? A Retrospective Cohort Study
}

\author{
Tesfay Mehari Atey $\left(\mathbb{D},{ }^{1}\right.$ Helen Bitew $\left(\mathbb{D},{ }^{2}\right.$ Solomon Weldegebreal Asgedom $\left({ }^{1},{ }^{1}\right.$ \\ Asrat Endrias, ${ }^{3}$ and Derbew Fikadu Berhe ${ }^{4}{ }^{4}$ \\ ${ }^{1}$ Clinical Pharmacy Unit, School of Pharmacy, College of Health Sciences, Mekelle University, Mek'ele, Ethiopia \\ ${ }^{2}$ Department of Pharmacognosy, School of Pharmacy, College of Health Sciences, Mekelle University, Mek'ele, Ethiopia \\ ${ }^{3}$ Medical Biochemistry, Biomedical Institute, College of Health Sciences, Mekelle University, Mek'ele, Ethiopia \\ ${ }^{4}$ Department of Pharmacology, School of Pharmacy, College of Health Sciences, Mekelle University, Mek'ele, Ethiopia
}

Correspondence should be addressed to Tesfay Mehari Atey; tesfay.mehari@mu.edu.et

Received 27 June 2019; Revised 26 September 2019; Accepted 9 December 2019; Published 21 January 2020

Academic Editor: Bhaskaran Unnikrishnan

Copyright (c) 2020 Tesfay Mehari Atey et al. This is an open access article distributed under the Creative Commons Attribution License, which permits unrestricted use, distribution, and reproduction in any medium, provided the original work is properly cited.

\begin{abstract}
Objectives. Early antiretroviral therapy (ART), isoniazid preventive therapy (IPT), and isoniazid-rifapentine (3HP) are effective strategies for preventing tuberculosis (TB) among people living with HIV (PLHIV). The study aimed to determine the effect of IPT on the TB incidence, follow-up CD4 ${ }^{+}$T cells, and all-cause mortality rate. Participants. Eligible patients on ART $(n=1,863)$ were categorized into one-to-two ratios of exposed groups to IPT $(n=621)$ and nonexposed groups to IPT $(n=1,242)$. Exposed groups entered the cohort at their first prescription of IPT, and unexposed groups entered into the study at the first prescription of ART and then followed until the occurrence of the outcome or date of administrative censoring (June 30,2017). The outcome endpoints were TB incidence, follow-up CD4 ${ }^{+} \mathrm{T}$ cells, and all-cause mortality rate. Results. The follow-up $\mathrm{CD} 4^{+} \mathrm{T}$ cells for the exposed and nonexposed groups were 405.74 and 366.95 cells $/ \mathrm{mm}$ (World Health Organization (WHO), 2017), respectively, a statistically significant finding $\left(t_{1861}=-3.770, p<0.0001\right.$; Cohen's $\left.d=0.186\right)$. Nine percent of the exposed patients $(620$ incidence of TB per 100,000 person-years (PYs)) and 21.9\% of the nonexposed patients (3160 incidence of TB per 100,000 PYs) developed TB. Mortality rate (per 100,000 PYs) was 440 for the exposed and 1490 for the unexposed patients. Statistically significant determinants of the all-cause mortality were unscheduled follow-up (AHR $=1.601 ; 95 \%$ CI: 1.154-2.222) and unable to work properly $(\mathrm{AHR}=2.324 ; 95 \% \mathrm{CI}: 1.643-3.288)$. Conclusion. This study demonstrates the effect of IPT in reducing incidence of TB and allcause mortality rate and improving follow-up $\mathrm{CD} 4^{+} \mathrm{T}$ cells. Promoting IPT use can help to achieve the TB eradicating national agenda in Ethiopia.
\end{abstract}

\section{Introduction}

As one of the most serious opportunistic infections (OIs) among people living with HIV/AIDS (PLHIV), tuberculosis (TB) often leads to mortality in low-income African countries $[1,2]$. HIV/AIDS accelerates the reactivation of latent TB infection (LTBI) and rapid progression to primarily TB [3-7], and vice versa [7]. The progression of LTBI to active disease during the lifetime of the general population is about $5-10 \%$, compared to $30 \%$ among PLHIV coinfected with TB $[6,8,9]$. This rapid progression is more likely to happen within the first years of infection [10].

The 2016 global report estimated about 6.3 million incident cases of TB, equivalent to $61 \%$ of the estimated incidence of 10.4 million. There were 476,774 reported cases of HIV/TB coinfections, in which $85 \%$ were on antiretroviral therapy (ART) [3]. The prevalence of LTBI included about a quarter to one-third of the global population $[7,11]$. Rates of LTBI are $49 \%$ in Uganda [12], 55.2\% in South Africa [13], and ranged from $31.2 \%$ to $64 \%$ in Ethiopia [14-16]. In Tigray 
(Northern Ethiopia), the prevalence of HIV was $4.7 \%$ among adults [17] and the number of PLHIV in the region is estimated to be 117,976 even though the effort at reduction of mortality is not adequate. The overall weighted prevalence of bacteriologically confirmed pulmonary TB in the Tigray region was found to be $216 / 100,000$ [18].

Some preventive strategies such as ART, IPT, and isoniazid-rifapentine (3HP) are required to reduce the risk of LTBI progression to active disease to achieve the 2035 target of eliminating TB $[10,19-21]$. Several studies have explored the effect of IPT on mortality [22-25]. However, coverage and uptake of IPT is not $100 \%$ [2], and IPT coverage in the region was estimated to be $20 \%$ in which fear of creating isoniazid resistance and lack of commitment of health managers to scale-up the program were some of the main barriers hindering implementation of IPT [26].

The effect of IPT together with ART on the CD $4^{+}$T cells and rate of mortality among PLHIV on chronic HIV care follow-up is poorly understood with conflicting results. Reduction of all-cause mortality was not evidenced in some studies $[8,19]$. The use of IPT among PLHIV is associated with a significant reduction in incidence of TB [19]. Although the TB-related mortality benefits were revealed by randomized controlled trials of IPT, all-cause mortality reduction was not significantly shown $[27,28]$. In addition, the applicability of the data obtained from other context could have limitations due to the variability in clinical cohorts in different populations. IPT is also largely affected by the population genetics. Hence, the primary aim of the present study was to determine whether IPT lowers the incidence of TB and rate of all-cause mortality and improves the $\mathrm{CD} 4^{+}$T cells independent effect of ART on the incidence of TB, $\mathrm{CD}^{+}{ }^{\mathrm{T}}$ cells, and mortality among PLHIV in Tigray region, Ethiopia.

\section{Methods}

2.1. Study Settings. A regional-based propensity-matched retrospective cohort study was conducted in six ART clinics of selected hospitals in Northern Ethiopia, Tigray Regional State. We selected six sites, namely, Alamata Hospital, Ayder Comprehensive Specialized Hospital, Lemlem Karl Hospital, St. Marry Hospital, Suhul Hospital, and Wukro Hospital, randomly from the 14 hospitals [29] using a lottery method. World Health Organization guidelines have expanded the recommended criteria for life-saving ART eligibility among people with HIV infection, though major changes in ART eligibility criteria have been observed during different periods including 2010, 2013, and 2016 [30].

2.2. Sample Size and Sampling Technique. The Kelsey method was employed in the sample size determination [31]. Accordingly, we used $5 \%$ for two-tailed type-I error, $80 \%$ power, two-sided $95 \%$ confidence interval (CI), unexposed to exposed ratio $=2: 1$, and 0.75 for minimum risk ratio to detect. From a previous study, 10\% prevalence and $4.5 \%$ prevalence of mortality among unexposed and exposed groups, respectively, were reported [25]. Adding a design effect of 1.5, a total of 621 patients were considered as exposed groups. Doubling this number, 1,242 subjects were included in the nonexposed group with a total of 1,863 patients.

A two-stage sampling technique, stratified sampling technique followed by a simple random sampling technique, was employed. From the total of 1,863 study participants, 310 patients were stratified into the six ART clinics. These 310 study patients were selected using a computer-generated simple random sampling technique at each clinic who started their ART and/or IPT starting from the index period using their unique ART identification number. Out of these 310 study patients per a clinic, 103 exposed patients were first randomly selected from patients taking IPT and ART. For every exposed patient, two unexposed patients (on ART alone) were randomly selected after adjustment for the WHO clinical stage, baseline $\mathrm{CD} 4^{+} \mathrm{T}$ cells count, treatment categories, and adherence status (Figures 1 and 2).

2.3. Inclusion and Exclusion Criteria. Eligible patients were selected based on the following criteria: PLHIV having at least two or more visits starting from the index period and receiving their healthcare at the clinics. On the contrary, PLHIV were on anti-TB treatment before the enrollment, with altered or elevated liver function tests at baseline (five times higher than the upper normal limits in asymptomatic patients or three times above the upper normal limits in symptomatic patients), with adherence rate of $<85 \%$ or missed $\geq 6$ doses out of 30 doses, and with unknown period (month and year) of starting both regimens and treatment outcome were excluded from the study (Figure 1 and Supplementary Figure 1). Determination of TB incidence, biannual $\mathrm{CD}^{+}{ }^{+} \mathrm{T}$ cells counts, and mortality status was the treatment outcome variables.

2.4. Data Collection. A customized data collection form was adopted from the format of Federal Ministry of Health. The data abstraction form was piloted before implementation, and 12 data collectors, who were recruited from the staff members of the hospital and trained as data collectors for two days, collected the data. The patients' medical records were followed until occurrence of the outcome (incidence of TB and mortality) or date of administrative censoring (end period of data collection, i.e., June 30, 2017). Completeness of the collected data was supervised and monitored adequately by the investigators and supervisors during the data collection process. The duration of IPT is 6 months, and it is given at a daily dose of $5 \mathrm{mg} / \mathrm{kg}$ (maximum $300 \mathrm{mg}$ ). IPT and ART visits were given as integrative services at the clinic.

2.5. Operational Definitions. Unscheduled follow-up was defined when the participant did not attend at least one routine follow-up visit on the appointment date. Otherwise, the participant was deemed to have a scheduled follow-up.

The index period was identified when exposed groups entered the cohort at their first prescription of IPT, and 


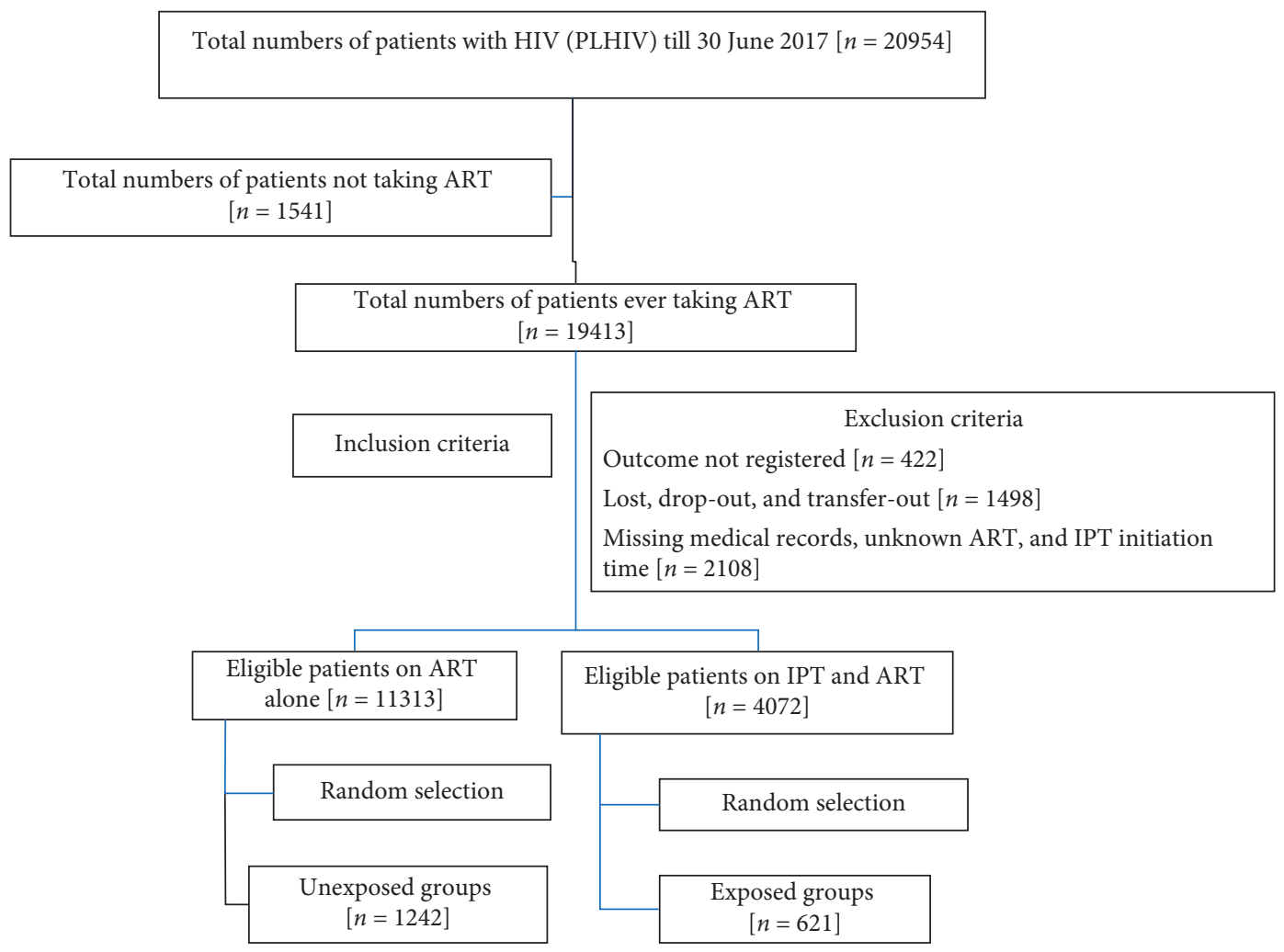

FIgURE 1: A flow diagram showing selection of study patients on IPT plus ART and ART alone.

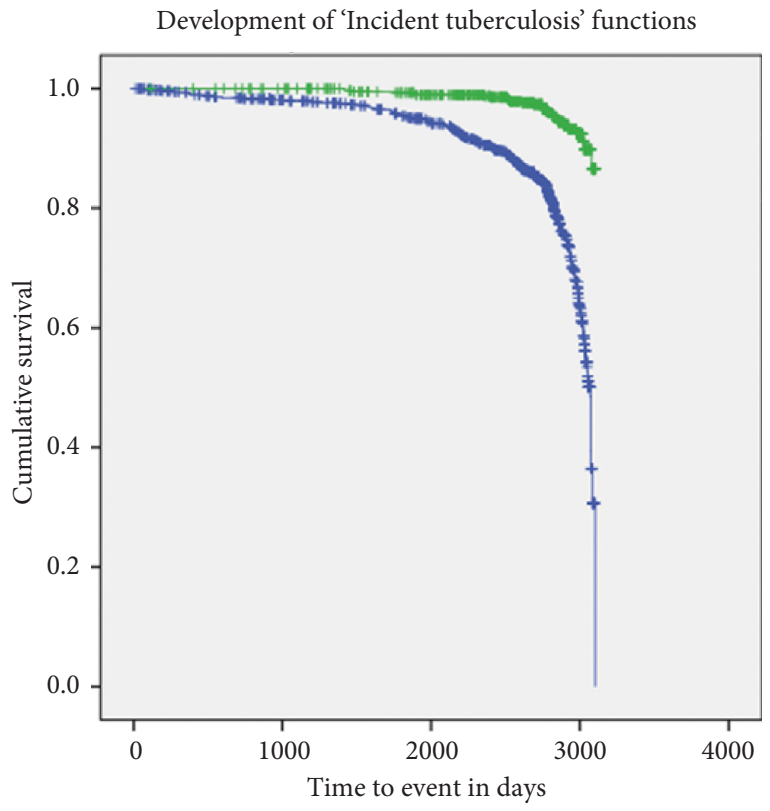

Exposure to IPT

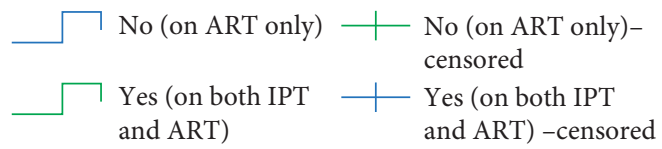

FIGURE 2: Kaplan-Meier for incidence of TB among patients living with HIV/AIDS taking IPT and ART versus ART alone in Northern Ethiopia, 2009-2017. unexposed groups entered into the study at the first prescription of ART.

Diagnosis of TB was done according to the Ethiopian Tuberculosis, Leprosy and TB/HIV Prevention and Control Program Manual [32], where all suspects of any form of TB must be examined according to the standardized diagnostic procedures in which the microscopic examination of sputum is the most important and reliable one, followed by radiological investigation, acid fast bacilli (AFB) culture, and histopathology. The identification of TB suspects (cough for more than two weeks) and followed by screening them by examination of sputum smears are performed during every visit or at every suspicion of $\mathrm{TB}$.

2.6. Data Analysis. Data were analyzed using Statistical Package for Social Sciences (SPSS ${ }^{\circledR}$ Statistics) program version 21 (SPSS; Chicago, IL, USA), STATA ${ }^{\circledR}$ version 12 , and $\mathrm{R}^{\circledR}$-software ( $\mathrm{R}$ i386 2.15.3). Kaplan-Meier (KM) analyses were used to compare the mortality rates and $\mathrm{TB}$ incidence-free survival time between the two cohorts. The assumption for proportional hazard was assessed graphically by log minus log survival curve (Supplementary Figure 2) and a time-dependent Cox-model ( $p$-value for $\left.\mathrm{T} \_\mathrm{COV}=0.778\right)$. A sensitivity analysis, using propensity score matching, was performed to evaluate and address confounding by indication (Appendix in Supplementary materials). 
An independent samples $t$-test was used to compare the follow-up $\mathrm{CD}^{+} \mathrm{T}$ cells between the two cohorts. Moreover, TB incidence and incidence rates of mortality per 100,000 persons-years (PYs) of follow-up were employed. We used exact dates to calculate person-years by summing of total time contributed by all subjects. In the propensity-matched cohort, an adjusted Cox proportional hazard model was repeated to find out the effects of sociodemographics, clinical characteristics, and treatment categories on the outcome variables. Cohen's $d$ was used as an index for determining the strength of the effect size. In all the analyses, significance testing was done using two-sided $p$ values and $95 \% \mathrm{CI}$, and a $p$ value $<0.05$ was considered as statistically significant. Lastly, missing data for continuous variables were accounted by the expectation maximization model.

2.7. Patient and Public Involvement. This study was conducted in medical records of patients using standardized formats prepared by the Ethiopian Federal Ministry of Health, and hence, there was no direct involvement of the patients and the public.

2.8. Ethical Considerations. An ethical clearance was obtained from "Health Research and Ethics Review Committee" of College of Health Sciences (Reference number: ERC 0877/2016), Mekelle University. In addition, the Research Committee of Tigray Regional Health Bureau granted ethical permission to conduct the study (Reference number: 4366/7767/09). Permission to utilize patient data was also obtained officially from the administrative offices of the selected hospitals. To ensure confidentiality, name and other identifiers of patients, physicians, and other staff members of the centers were not recorded on the data abstraction instrument.

This study was funded by Mekelle University (Grant Number: CRPO/CHS/SM/015/09). The funder of the study had no role in study design, data collection, data analysis, data interpretation, or writing of the report. The corresponding author had full access to all the data in the study and had final responsibility for the decision to submit for publication. Lastly, this study was done in accordance with STROBE cohort reporting guidelines [33].

\section{Results}

3.1. Sociodemographic and Clinical Characteristics. Nearly one-third of females (34.9\%) and males (30.9\%) were exposed to IPT. Comparably, about one in three of the participants in the age group of 30-44 (34.1\%) and participants dwelling in urban areas (33.5\%) were exposed to IPT. Approximately one-third of the patients had a working functional status $(33.7 \%)$, and those participants with a WHO clinical stage III at the baseline (38.9\%) were exposed to IPT (Table 1).

In follow-up, $61.4 \%$ of the visits were scheduled and $38.6 \%$ of the visits were unscheduled. The average baseline body weight was almost similar in both groups: exposed patients $(49.8 \mathrm{~kg})$ and unexposed patients $(49.2 \mathrm{~kg})$. The
TABLE 1: Baseline sociodemographic and clinical characteristics of patients living with HIV/AIDS in Northern Ethiopia, 2009-2017.

\begin{tabular}{|c|c|c|c|}
\hline \multirow[b]{2}{*}{ Variables } & & \multicolumn{2}{|c|}{ Exposure to IPT } \\
\hline & & $\begin{array}{c}\text { No (ART } \\
\text { alone) }\end{array}$ & $\begin{array}{c}\text { Yes (IPT } \\
\text { and ART) }\end{array}$ \\
\hline \multirow{2}{*}{ Sex } & Male & $\begin{array}{c}500 \\
(69.2 \%)\end{array}$ & $223(30.8 \%)$ \\
\hline & Female & $\begin{array}{c}742 \\
(65.1 \%)\end{array}$ & $398(34.9 \%)$ \\
\hline \multirow{5}{*}{ Age (in years) } & $<15$ & $\begin{array}{c}75 \\
(63.0 \%)\end{array}$ & $44(37.0 \%)$ \\
\hline & $15-29$ & $\begin{array}{c}235 \\
(70.4 \%)\end{array}$ & $99(29.6 \%)$ \\
\hline & $30-44$ & $\begin{array}{c}698 \\
(65.9 \%)\end{array}$ & $361(34.1 \%)$ \\
\hline & $45-59$ & $\begin{array}{c}210 \\
(66.5 \%)\end{array}$ & $106(33.5 \%)$ \\
\hline & $\geq 60$ & $\begin{array}{c}24 \\
(68.6 \%)\end{array}$ & $11(31.4 \%)$ \\
\hline \multirow{2}{*}{ Residence } & Rural & $\begin{array}{c}412 \\
(67.0 \%)\end{array}$ & $203(33.0 \%)$ \\
\hline & Urban & $\begin{array}{c}930 \\
(66.5 \%)\end{array}$ & $418(33.5 \%)$ \\
\hline \multirow{3}{*}{ Functional status } & Working & $\begin{array}{c}827 \\
(66.3 \%)\end{array}$ & $420(33.7 \%)$ \\
\hline & Ambulatory & $\begin{array}{c}318 \\
(66.4 \%)\end{array}$ & $161(33.6 \%)$ \\
\hline & Bedridden & $\begin{array}{c}97 \\
(70.8 \%)\end{array}$ & $40(29.2 \%)$ \\
\hline \multirow{4}{*}{$\begin{array}{l}\text { World Health } \\
\text { Organization clinical } \\
\text { staging }\end{array}$} & Stage I & $\begin{array}{c}178 \\
(63.1 \%)\end{array}$ & $104(36.9 \%)$ \\
\hline & Stage II & $\begin{array}{c}251 \\
(61.1 \%)\end{array}$ & $160(38.9 \%)$ \\
\hline & Stage III & $\begin{array}{c}649 \\
(68.7 \%)\end{array}$ & $296(31.3 \%)$ \\
\hline & Stage IV & $\begin{array}{c}164 \\
(72.9 \%)\end{array}$ & $61(27.1 \%)$ \\
\hline
\end{tabular}

AIDS: acquired immune deficiency syndrome; ART: antiretroviral therapy; HIV: human immunodeficiency virus; IPT: isoniazid preventive therapy.

average baseline BMI was also about $19.8 \mathrm{~kg} / \mathrm{m}^{2}$ for both cohorts. Over the nine-year period, the weight was increased by about $6.6 \mathrm{~kg}$ for both cohorts; and the BMI was increased by $2.8 \mathrm{~kg} / \mathrm{m}^{2}$ for the exposed group and by $3.8 \mathrm{~kg} / \mathrm{m}^{2}$ for the unexposed group, interpreting into about $15 \%$ and $16 \%$ increase from baseline to 2017, respectively (Supplementary Figure 3).

Nearly one-third $(32.31 \%)$ of the patients were initiated with $\mathrm{d} 4 \mathrm{~T}+3 \mathrm{TC}+\mathrm{NVP}$ followed by AZT $+3 \mathrm{TC}+\mathrm{NVP}$, in which this regimen was taken by about a quarter of the patients $(24.3 \%)$. Majority of the study participants (93.5\%) were on the first line ART regimen. The mean duration on ART for both groups was 6.8 years. Furthermore, the average time between ART initiation and IPT initiation is 239 days.

3.2. Effect of IPT on Tuberculosis. From the total patients, $16.1 \%$ of them developed TB, in which $9.3 \%$ of the exposed groups and $21.9 \%$ of the unexposed groups developed TB $(p<0.0001)$ (Table 2). 
TABLE 2: Incidence of tuberculosis among patients living with HIV/AIDS taking IPT and ART versus ART alone in Northern Ethiopia, 2009-2017.

\begin{tabular}{|c|c|c|c|c|c|}
\hline \multirow{2}{*}{ Disease/exposure } & & \multicolumn{2}{|c|}{ Exposure to IPT } & \multirow{2}{*}{ Total } & \multirow{2}{*}{$p$ value } \\
\hline & & No (on ART only) & Yes (IPT and ART) & & \\
\hline & No & $970(78.1 \%)$ & $593(95.5 \%)$ & $1563(83.9 \%)$ & \\
\hline Development of tuberculosis & Yes & $272(21.9 \%)$ & $28(4.5 \%)$ & $300(16.1 \%)$ & \\
\hline Incidence rate of TB (per 100,000 persons-years) & Total & $\begin{array}{l}1242(100.0 \%) \\
3160\end{array}$ & $\begin{array}{l}621(100.0 \%) \\
620\end{array}$ & $1863(100.0 \%)$ & $<0.0001$ \\
\hline
\end{tabular}

On average, the time to development of TB incidence post-IP exposure was 926 days (two and half years). The incidence rate of TB (per 100,000 PYs) was 620 (incidence rate difference $=-2250 ; 95 \%$ CI: -3000 to $-2110 ; p$ value $<0.0001$ ) for the exposed groups and 3160 (incidence rate ratio $=2340 ; 95 \%$ CI: 1530 to 3470 ) for the unexposed groups (Table 2). The KM analysis for the incidence of TB illustrated that unexposed patients had more chance of developing TB than exposed patients $(p<0.0001)$ (Figure 2$)$

3.3. Effect of IPTon $C D 4^{+}$T Cells. The mean follow-up $\mathrm{CD} 4^{+}$ $\mathrm{T}$ cells (in cells per $\mathrm{mm}^{3}$ ) were 405.74 for IPT exposed patients and 366.95 for IPT unexposed patients. For the exposed group, the $\mathrm{CD} 4^{+}$T cells showed increase by $177.61 \%$ (i.e., 344.81 cells per $\mathrm{mm}^{3}$ ) over the past nine years, with an average of 538.94 in 2017, up from a mean of 194.14 at the baseline. Likewise, for the second cohort, the $\mathrm{CD}^{+}{ }^{+} \mathrm{T}$ cells showed increase by $187.67 \%$ (i.e., 333.58 cells per $\mathrm{mm}^{3}$ ) over the past nine years, with an average of 511.33 in 2017, up from a mean of 177.75 at the baseline (Figure 3).

After propensity score matching, there was a statistically significant difference in mean $\mathrm{CD} 4^{+} \mathrm{T}$ cells between the two cohorts $\left(t_{1861}=-3.770, p<0.0001\right)$. The average CD4 ${ }^{+} \mathrm{T}$ cells for patients not exposed to IPT (mean $=366.951 \mathrm{cells} / \mathrm{mm}$ [3]; $\mathrm{SD}=209.827$ cells $/ \mathrm{mm}^{3}$ ) was 38.792 cells $/ \mathrm{mm}^{3}$ (95\% CI: -58.970 to -18.614 cells $/ \mathrm{mm}^{3}$ ) lower than the average CD4 ${ }^{+}$ T cells for patients exposed to IPT (mean $=405.742$ cells $/ \mathrm{mm}$ [3]; $\mathrm{SD}=208.348$ cells/mm [3]; Cohen's $d=0.186$ ). The mean CD4 cells in different years are given in Table 3.

The total person-years (PYs) of observation for patients exposed to IPT and for those not exposed to IPT were 4,512 and 8,567 , respectively. The incidence rate of mortality was 440 per 100,000 PYs (incidence rate difference $=-1050 ; 95 \%$ CI: -1270 to -730 per 100,000 PYs; $p$ value $<0.0001$ ) for the exposed groups and 1490 per 100,000 PYs (incidence rate ratio $=3560 ; 95 \%$ CI: 2100 to 3980 per 100,000 PYs) for the unexposed groups. The KM analysis for survival function illustrated that exposed patients had a better survival chance than unexposed patients at all levels of time $(p<0.0001)$ (Figure 4).

Statistically significant preventive factors from mortality were urban residence compared to rural residence $(\mathrm{AHR}=0.595 ; 95 \%$ CI: 0.427-0.831), CD4+ T (in cells per $\left.\mathrm{mm}^{3}\right) \geq 250$ compared to $<250(\mathrm{AHR}=0.217 ; 95 \% \mathrm{CI}$ : $0.154-0.307$ ), and exposure to IPT (AHR $=0.339 ; 95 \%$ CI: $0.211-0.545)$. On the other hand, unscheduled follow-up $(\mathrm{AHR}=1.601 ; 95 \% \mathrm{CI}: 1.154-2.222)$ and unable to work properly $(\mathrm{AHR}=2.324 ; 95 \% \mathrm{CI}: 1.643-3.288)$ were statistically associated with mortality (Table 4 ).

\section{Discussion}

The use of IPT with ART regimen significantly reduced allcause mortality and incidence of $\mathrm{TB}$ and improved $\mathrm{CD} 4^{+}$ T cells, as evidenced in this study. The mortality benefit due to the initiation of IPT is evidenced in other studies conducted in Ethiopia [25], Tanzania [34], and South Africa [35]. Moreover, the initiation of IPT was significantly associated with reduced TB-caused mortality [36-38], allcause mortality [39, 40], and illness among PLHIV [41].

Without this protective effect, an increased hazard of $\mathrm{TB}$ on mortality was described [42] as HIV-related TB is the leading infectious cause of death worldwide [43]. However, the use of IPT in reduction of mortality was not always found to be significant, as reported in the previous studies $[8,27,36,44-46]$.

The incidence of $\mathrm{TB}$ is found to be about five times more among unexposed groups compared to the exposed cohort, which is in line with a chemoprophylaxis study done in Brazil that provided similar evidence [8]. One cohort study described 11 cases of TB (among 316 patients observed during a two-year follow-up) with the incidence of TB in the IPT group reported to be 3.5 cases per 100 persons per year [47]. In another study, eight of $130 \mathrm{HIV}$-infected patients who received IPT for nine months developed TB during a 43-month follow-up period [48].

Effectiveness of IPT on new incidence of TB has been suggested in different local studies from Ethiopia and in other countries such as South Africa, Uganda, and Ivory coast $[25,36,48-52]$. Indeed, some studies from Ethiopia and South Africa involved PLHIV who have not started ART $[25,35]$. Despite IPT's impact against new development of TB, IPT's long-term protection against TB is still ambiguous. Many African studies stated that the chemoprophylaxis prevented PLHIV from TB while receiving IPT only. Immediately after IPT's duration of action, its protection effect was found to be weakened [40, 44, 53-57]. On the contrary, studies conducted in US, Mexico, and Brazil did not find any waning effect of TB protection $[44,49,51]$. On the contrary, Rangaka et al. study done in South Africa found a steady rise of TB incidence rate after one year of IPT termination [57].

About twice as many patients residing in rural areas were experiencing death compared to patients living in urban areas. This finding may be tied to the presence of less followup, care and treatment; lesser awareness regarding the complications of the disease and OIs; and higher preponderance to lost and drop-out for patients residing in rural areas compared to urban areas. On the contrary, patients whose follow-up was scheduled were less likely to die than patients whose follow-up was unscheduled, and on-time 


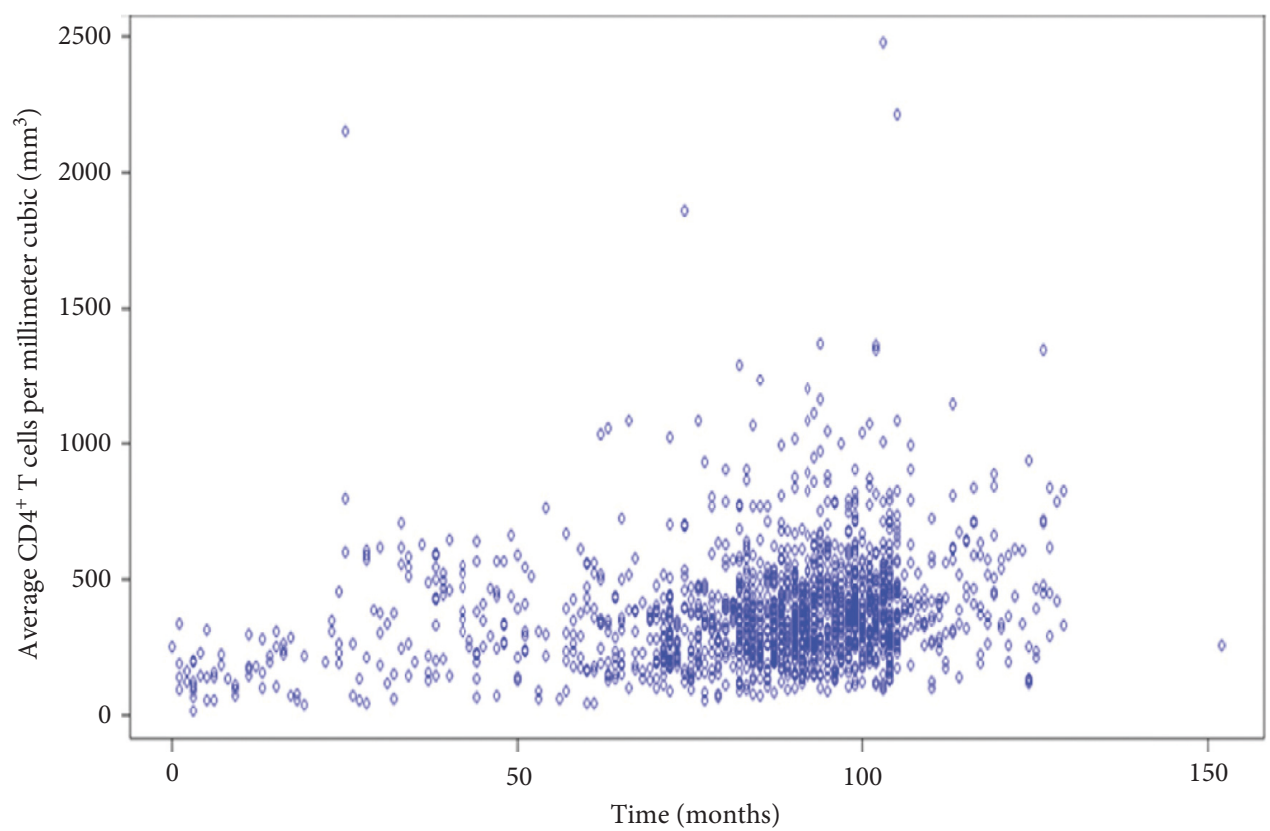

(a)

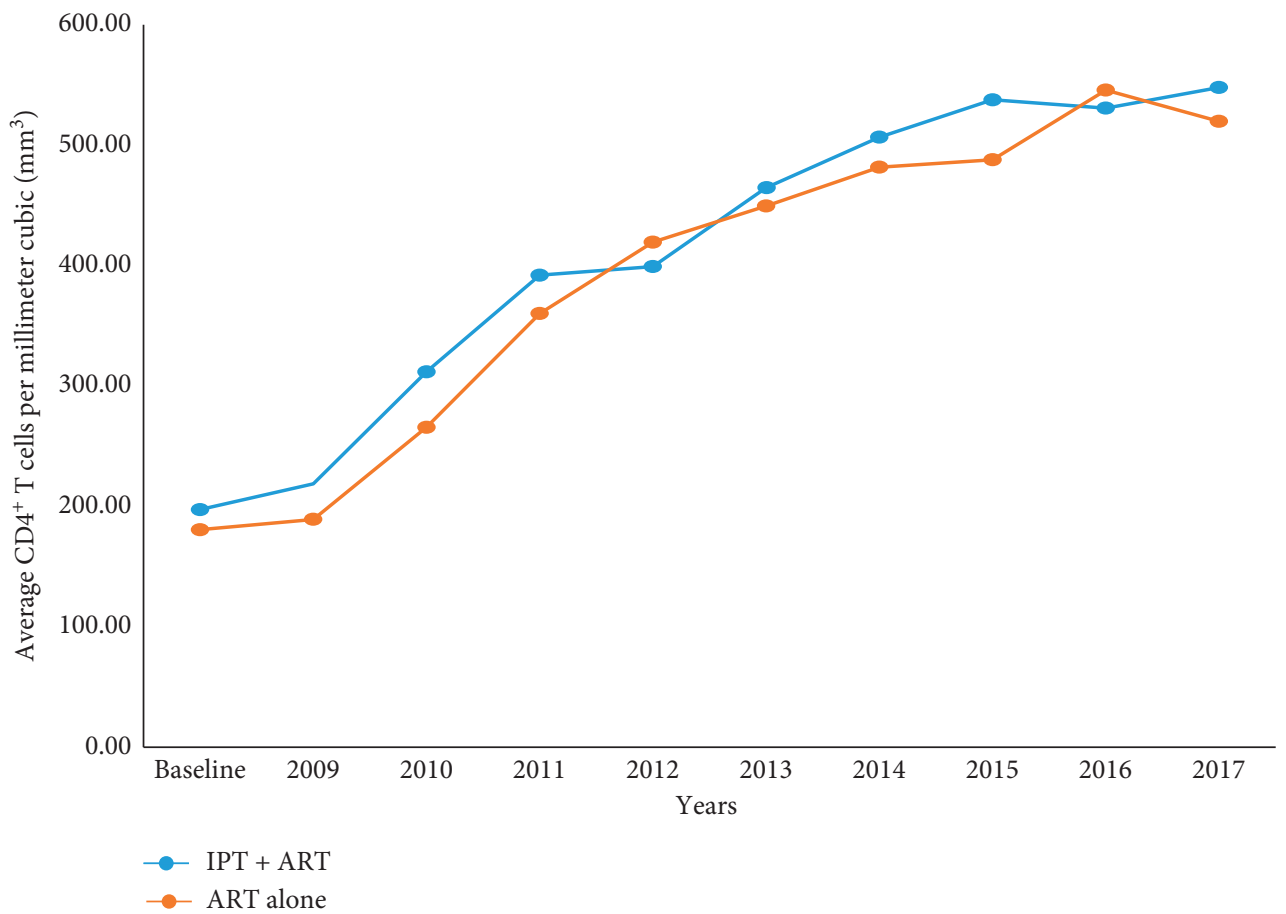

(b)

Figure 3: Continued. 


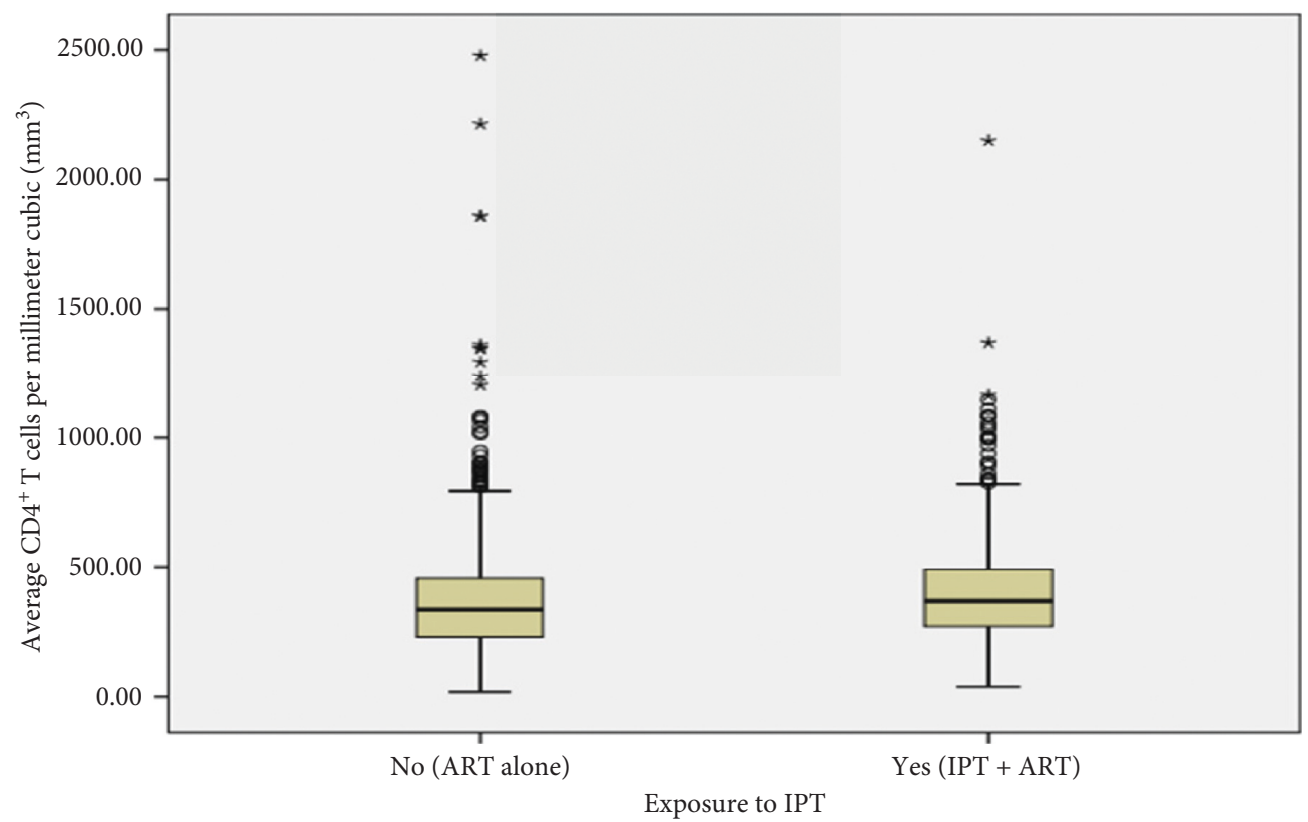

(c)

FIgure 3: Trend of $\mathrm{CD}^{+} \mathrm{T}$ cells per millimeter cubic among patients living with HIV/AIDS taking IPT and ART versus ART alone in Northern Ethiopia, 2009-2017. (a) Overall CD4 $4^{+} \mathrm{T}$ cell trends; (b) trend comparison by cohorts; (c) mean CD4 ${ }^{+} \mathrm{T}$ cells comparison by cohorts. AIDS: acquired immune deficiency syndrome; ART: antiretroviral therapy; CD4+ T cells: cluster of differentiation 4 positive T cells; HIV: human immunodeficiency virus; IPT: isoniazid preventive therapy.

TABLE 3: One-way ANOVA result of CD4 cells among patients living with HIV/AIDS taking IPT and ART versus ART alone in Northern Ethiopia, 2009-2017.

\begin{tabular}{lcc}
\hline & Exposure to IPT & Mean CD4 cells per cubic millimeter + SEM \\
\hline \multirow{2}{*}{ Baseline } & Unexposed group (on ART alone) & $177.75 \pm 3.24$ \\
& Exposed group (on IPT + ART) & $194.14 \pm 6.33^{*}$ \\
2009 & Unexposed group (on ART alone) & $186.12 \pm 3.76$ \\
& Exposed group (on IPT + ART) & $215.18 \pm 6.22^{* *}$ \\
2010 & Unexposed group (on ART alone) & $261.38 \pm 4.77$ \\
& Exposed group (on IPT + ART) & $306.7 \pm 7.70^{*}$ \\
2011 & Unexposed group (on ART alone) & $354.33 \pm 6.76$ \\
& Exposed group (on IPT + ART) & $385.69 \pm 10.61$ \\
2012 & Unexposed group (on ART alone) & $392.67 \pm 6.74$ \\
& Exposed group (on IPT + ART) & $412.66 \pm 10.59$ \\
2013 & Unexposed group (on ART alone) & $442.15 \pm 9.02$ \\
& Exposed group (on IPT + ART) & $457.16 \pm 11.51$ \\
2014 & Unexposed group (on ART alone) & $473.91 \pm 9.78$ \\
& Exposed group (on IPT + ART) & $498.38 \pm 11.69$ \\
2015 & Unexposed group (on ART alone) & $479.97 \pm 8.40$ \\
& Exposed group (on IPT + ART) & $528.92 \pm 12.54^{* *}$ \\
2016 & Unexposed group (on ART alone) & $522.13 \pm 9.34$ \\
2017 & Exposed group (on IPT + ART) & $536.84 \pm 10.91$ \\
& Exposed group (on IPT + ART) & $511.33 \pm 9.00$ \\
\hline
\end{tabular}

${ }^{*}$ Statistically significant $p$ value $<0.05 ;{ }^{* *}$ statistically significant $p$ value $<0.01$. Effect of IPT on all-cause mortality and associated factors.

scheduling may be associated with good adherence to the long-term medications.

There is fivefold more risk of death among patients with low CD4 count compared to patients with higher CD4 count. Several other studies are consistent with this finding, and they also pointed to the fact that severe immune suppression is observed in those with $\mathrm{CD} 4+\mathrm{T}$ cell count below 200 cells $/ \mathrm{mm}^{3}$ [58, 59]. Institutional-based crosssectional study conducted in Ethiopia reported that $79.5 \%$ of $\mathrm{TB}$ infection occurred in low $\mathrm{CD} 4^{+} \mathrm{T}$ cells level $(<200$ cells/ $\mathrm{mm}^{3}$ ). This increases morbidity and hastens progression of HIV to AIDS and mortality [60]. 


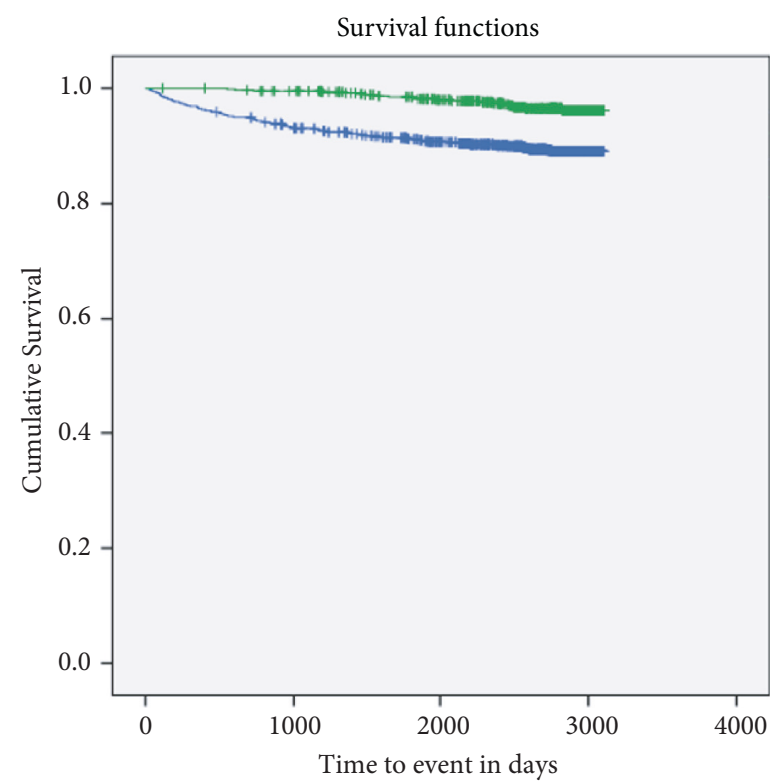

Exposure to IPT

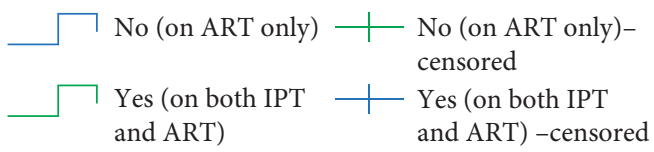

FIgURE 4: Kaplan-Meier survival analysis for patients living with HIV/AIDS taking IPT and ART versus ART alone in Northern Ethiopia, 2009-2017.

TABLE 4: Results of Cox regression analysis for factors associated with survival status among patients living with HIV/AIDS taking IPT and ART versus ART alone in Northern Ethiopia, 2009-2017.

\begin{tabular}{|c|c|c|c|c|c|c|c|}
\hline Variable & & $\begin{array}{c}\text { Survival } \\
\text { status } \\
\text { Alive, } n(\%)\end{array}$ & Death, $n(\%)$ & CHR [95\% CI] & $p$ value & AHR $[95 \% \mathrm{CI}]$ & $p$ value \\
\hline \multirow[t]{2}{*}{ Sex } & Female & $1,076(94.4)$ & $64(5.6)$ & $\begin{array}{c}0.465 \\
{[0.336-0.643]}\end{array}$ & $<0.0001^{* *}$ & $\begin{array}{c}0.691 \\
{[0.495-0.964]}\end{array}$ & $0.030^{*}$ \\
\hline & Male & $638(88.2)$ & $85(11.8)$ & Reference & & Reference & Reference \\
\hline \multirow{2}{*}{ Residence } & Urban & $1,161(93.0)$ & $87(7.0)$ & $\begin{array}{c}0.680 \\
{[0.491-0.941]}\end{array}$ & $0.020^{*}$ & $\begin{array}{c}0.595 \\
{[0.427-0.831]}\end{array}$ & 0.002 \\
\hline & Rural & $553(89.9)$ & $62(10.1)$ & Reference & & Reference & \\
\hline \multirow[t]{2}{*}{ Scheduling } & Unscheduled & $641(89.0)$ & $79(11.0)$ & $\begin{array}{c}0.712 \\
{[0.606-0.837]}\end{array}$ & $0.0001^{* *}$ & $\begin{array}{c}1.601 \\
{[1.154-2.222]}\end{array}$ & 0.005 \\
\hline & Scheduled & $1,073(93.9)$ & $70(6.1)$ & Reference & & Reference & \\
\hline \multirow{3}{*}{$\begin{array}{l}\text { Baseline functional } \\
\text { status }\end{array}$} & Bedridden (2) & $121(88.3)$ & $16(11.7)$ & $\begin{array}{c}2.163 \\
{[1.255-3.726]}\end{array}$ & 0.005 & $\begin{array}{c}1.617 \\
{[0.935-2.796]}\end{array}$ & 0.086 \\
\hline & $\begin{array}{c}\text { Ambulatory } \\
\text { (1) }\end{array}$ & $415(86.6)$ & $64(13.4)$ & $\begin{array}{c}2.515 \\
{[1.790-3.534]}\end{array}$ & $<0.0001^{* *}$ & $\begin{array}{c}2.324 \\
{[1.643-3.288]}\end{array}$ & $<0.0001^{* *}$ \\
\hline & Working & $1,178(94.5)$ & $69(5.5)$ & Reference & & Reference & \\
\hline \multirow{2}{*}{$\begin{array}{l}\text { CD } 4+\mathrm{T} \text { cells } \\
\text { (in cells } / \mathrm{mm}^{3} \text { ) }\end{array}$} & $\geq 250$ & $1,318(96.1)$ & $54(3.9)$ & $\begin{array}{c}0.176 \\
{[0.126-0.246]}\end{array}$ & $<0.0001^{* *}$ & $\begin{array}{c}0.217 \\
{[0.154-0.307]}\end{array}$ & $<0.0001^{* *}$ \\
\hline & $<250$ & $396(80.7)$ & $95(19.3)$ & Reference & $<0.0001^{* *}$ & Reference & \\
\hline \multirow[b]{2}{*}{ Exposure to IPT } & No & $1113(89.6)$ & $129(10.4)$ & Reference & & Reference & \\
\hline & Yes & $601(96.8)$ & $20(3.2)$ & $\begin{array}{c}0.296 \\
{[0.185-0.474]}\end{array}$ & $<0.0001^{* *}$ & $\begin{array}{c}0.339 \\
{[0.211-0.545]}\end{array}$ & $<0.0001^{* *}$ \\
\hline
\end{tabular}

"Statistically significant at $p<0.05$; ${ }^{* * *}$ statistically significant at $p<0.0001$. The following factors were analyzed at the crude stage: sex, age, place of residence, scheduling, baseline functional status, specific ARV regimen, body mass index, exposure variable, and WHO clinical staging. AHR: adjusted hazard ratio; ARV: antiretroviral regimen; BMI: body mass index; $\mathrm{CD}^{+}$T cells: cluster of differentiation 4 positive Tcells; CI: confidence interval; $\mathrm{CHR}$ : crude hazard ratio; WHO: World Health Organization. 


\section{Conclusions}

This study demonstrates the effect of IPT, when used with ART, in reducing incidence of $\mathrm{TB}$ and all-cause mortality rate and improving $\mathrm{CD}^{+} \mathrm{T}$ cells in Tigray region. Rural residence, lower $\mathrm{CD} 4+\mathrm{T}$ cell values, nonexposure to IPT, and having unscheduled follow-up were independent predictors of increased likelihood of the all-cause mortality. Moving forward, we call for the healthcare providers to closely monitor the treatment outcome of patients taking ART alone and place a special effort in optimizing the outcome. Promoting IPT use can help achieving the TB eradicating national agenda in Ethiopia.

\section{Data Availability}

The datasets supporting the conclusions of the study are included within the manuscript. Any additional data will be available on request by contacting the corresponding author through tesfay.mehari@mu.edu.et.

\section{Additional Points}

Strengths and Limitations of This Study. (i) This study was adequately powered to study the relationship between the effect of ART used alone and with IPT. (ii) This study employed a robust sample size and adequate number of events. (iii) TB diagnosis was presumptive or was based on sputum and chest X-ray results in most cases, which might have led to over- or underestimation of the actual number of $\mathrm{TB}$ cases. (iv) We excluded patients who were lost to followup, and these patients may have died and had lower CD4 counts and more advanced World Health Organization (WHO) disease stage putting them at a greater risk for TB as compared to those active in follow-up. (v) The study did not include variables such as anemia and other comorbidities in our analyses because of missing data.

\section{Conflicts of Interest}

The authors declare that there are no conflicts of interest.

\section{Authors' Contributions}

TMA was involved in the conception and design of the study, developed data collection tools, supervised data collection, analyzed data, and wrote the manuscript. AE, HB SWA, and DFB supervised data collection and were involved in writing and editing of the manuscript. All authors read and approved the final manuscript.

\section{Supplementary Materials}

Supplementary Figure 1. Numbers of target and study population and inclusion and exclusion criteria of the study patients in Tigray Region. Supplementary Figure 2. Log minus $\log$ function for assumption of the proportional hazard. Supplementary Figure 3. Trend of weight (A) and body mass index (B) among patients living with HIV/AIDS taking IPT and ART versus ART alone in Northern Ethiopia,
2009-2017. Supplementary Figure 4. Kaplan-Meier survival analysis for patients living with HIV/AIDS taking IPT and ART versus ART alone in Northern Ethiopia, 2009-2017. (Supplementary Materials)

\section{References}

[1] J. Chakaya, H. Getahun, R. Granich, and D. Havlir, "Confronting TB/HIV in the era of increasing anti-TBdrug resistance," Journal of the International AIDS Society, vol. 11, no. 1, p. $6,2008$.

[2] United Nations Programme on HIV/AIDS (UNAIDS), "Report on the global AIDS epidemic," Geneva, Switzerland, 2013, http://www.unaids.org/en/resources/campaigns/ globalreport2013/globalreport.

[3] World Health Organization (WHO), "Global TB control report," Geneva, Switzerland, 2017, http://www.who.int/ entity/tb/publications/global_report/Exec_Summary_13Nov2017. pdf?ua $=1$.

[4] G. J. Churchyard, F. Scano, A. D. Grant, and R. E. Chaisson, "Tuberculosis preventive therapy in the era of HIV infection: overview and Research priorities," The Journal of Infectious Diseases, vol. 196, no. s1, pp. S52-S62, 2007.

[5] S. D. Lawn, R. Wood, and R. J. Wilkinson, "Changing concepts of "latent tuberculosis infection" in patients living with HIV infection," Clinical and Developmental Immunology, vol. 2010, Article ID 980594, 9 pages, 2011.

[6] A. Pawlowski, M. Jansson, M. Skold, M. E. Rottenberg, and G. Ka llenius, "Tuberculosis and HIV Co-infection," PLOS Pathogens, vol. 8, no. 2, pp. 1-7, 2012.

[7] E. L. Corbett, C. J. Watt, N. Walker et al., "The growing burden of tuberculosis: global trends and interactions with the HIV epidemic," Archives of Internal Medicine, vol. 163, no. 9, pp. 1009-1021, 2003.

[8] C. T. Souza, Y. H. M. Hökerberg, S. J. B. Pacheco, V. C. Rolla, and S. R. L. Passos, "Effectiveness and safety of isoniazid chemoprophylaxis for HIV-1 infected patients from Rio de Janeiro," Memórias do Instituto Oswaldo Cruz, vol. 104, no. 3 , pp. 462-467, 2009.

[9] G. Chamie, A. Luetkemeyer, E. Charlebois, and D. V. Havlir, "Tuberculosis as part of the natural history of HIV infection in developing countries," Clinical Infectious Diseases, vol. 50, no. s3, pp. S245-S54, 2010.

[10] World Health Organization (WHO), Latent Tuberculosis Infection (LTBI), World Health Organization (WHO), Geneva, Switzerland, 2016, http://www.who.int/tb/areas-ofwork/preventive-care/ltbi_faqs/en/.

[11] R. M. Houben and P. J. Dodd, "The global burden of latent tuberculosis infection: a re-estimation using mathematical modelling," PLOS Medicine, vol. 13, no. 10, Article ID e1002152, 2016.

[12] F. N. Kizza, J. List, A. K. Nkwata et al., "Prevalence of latent tuberculosis infection and associated risk factors in an urban African setting," BMC Infectious Diseases, vol. 15, no. 1, pp. 165-173, 2015.

[13] H. Mahomed, T. Hawkridge, S. Verver et al., "Predictive factors for latent tuberculosis infection among adolescents in a high-burden area in South Africa," International Journal of Tuberculosis and Lung Disease, vol. 15, pp. 331-336, 2011.

[14] M. Legesse, G. Ameni, G. Mamo et al., "Community-based cross-sectional survey of latent tuberculosis infection in Afar pastoralists, Ethiopia, using QuantiFERON-TB Gold In-Tube and tuberculin skin test," BMC Infectious Diseases, vol. 11, pp. 89-97, 2011. 
[15] A. Bekele, S. Ashenafi, G. Aderay et al., "Latent tuberculosis among adult Ethiopian patients at chest clinic, tikur anbessa specialized hospital, addis ababa, Ethiopia," The Ethiopian Journal of Health Development, vol. 54, 2016.

[16] A. F. Dagnew, J. Hussein, M. Abebe et al., "Diagnosis of latent tuberculosis infection inhealthy young adults in a country with high tuberculosis burden and BCG vaccination at birth," BMC Research Notes, vol. 5, no. 1, p. 415, 2012.

[17] EAIDS Resource Center (ETHARC), ART Information and Statistics, 2016, http://www.etharc.org/tigray/statistics.htm.

[18] G. Berhe, F. Enqueselassie, E. Hailu et al., "Population-based prevalence survey of tuberculosis in the Tigray region of Ethiopia," BMC Infectious Diseases, vol. 13, no. 1, p. 448, 2013.

[19] J. E. Golub, V. Saraceni, S. C. Cavalcante et al., "The impact of antiretroviral therapy and Isoniazid preventive therapy on tuberculosis incidence in HIV-infected patients in Rio de Janeiro, Brazil," AIDS, vol. 21, no. 11, pp. 1441-1448, 2007.

[20] M. Uplekar, D. Weil, K. Lonnroth et al., "WHO's new end TB strategy," The Lancet, vol. 385, pp. 1799-1801, 2015.

[21] Centers for Disease Control and Prevention, Treatment Regimens for Latent TB Infection (LTBI), Centers for Disease Control and Prevention, Atlanta, GA, USA, 2017, https:// www.cdc.gov/tb/topic/treatment/ltbi.htm.

[22] V. F. Gomes, A. Andersen, G. Lemvik et al., "Impact of isoniazid preventive therapy on mortality among children less than 5 years old following exposure to tuberculosis at home in Guinea-Bissau: a prospective cohort study," BMJ Open, vol. 3, Article ID e001545, 2013.

[23] Temprano ANRS 12136 Study Group, “A trial of early antiretrovirals and isoniazid preventive therapy in Africa," The New England journal of medicine, vol. 373, no. 9, pp. 808-822, 2015.

[24] K. D. Yirdaw, D. Jerene, Z. Gashu et al., "Beneficial effect of isoniazid preventive therapy and antiretroviral therapy on the incidence of tuberculosis in people living with HIV in Ethiopia," PLoS One, vol. 9, no. 8, Article ID e104557, 2014.

[25] D. Edessa and J. Likisa, "A description of mortality associated with IPT plus ART compared to ART alone among HIVinfected individuals in addis ababa, Ethiopia : a cohort study," PLoS ONE, vol. 10, no. 9, Article ID e0137492, 2015.

[26] G. Teklay, T. Teklu, B. Legesse, K. Tedla, and E. Klinkenberg, "Barriers in the implementation of isoniazid preventive therapy for people living with HIV in Northern Ethiopia: a mixed quantitative and qualitative study," BMC Public Health, vol. 16, no. 1, p. 840, 2016.

[27] C. Akolo, I. Adetifa, S. Shepperd, and J. Volmink, "Treatment of latent tuberculosis infection in HIV infected persons," Cochrane Database of Systematic Reviews, vol. 1, 2004.

[28] A. D. Grant, K. L. Fielding, S. Charalambous, R. E. Chaisson, and G. J. Churchyard, "Why have trials of isoniazid preventive therapy among people with HIV infection not demonstrated an effect on mortality? Did close examination of the trees obscure our view of the wood?," AIDS, vol. 24, pp. S15-S8, 2010.

[29] Ethiopian Federal Ministry of Health (FMoH), Health Infrastructure of Tigray Regional Health Bureau, Federal Ministry of Health, Addis Ababa, Ethiopia, 2012, http://www. moh.gov.et/tigrayhb.

[30] A. Burrage, M. Patel, K. Mirkovic et al., "Trends in antiretroviral therapy eligibility and coverage among children Aged $<15$ Years with HIV infection-20 PEPFAR-supported sub-saharan african countries," MMWR. Morbidity and Mortality Weekly Report, vol. 67, no. 19, pp. 552-555.
[31] J. L. Kelsey, A. S. Whittemore, A. S. Evans, and W. D. Thompson, Methods in Observational Epidemiology, Oxford University Press, Oxford, UK, 1996.

[32] Federal Ministry of Health Ethiopia, Tuberculosis, Leprosy and TB/HIV Prevention and Control Programme Manual, Federal Ministry of Health Ethiopia, Addis Ababa, Ethiopia, 4th edition, 2008.

[33] E. Von Elm, D. G. Altman, and M. Egger, “The Strengthening the Reporting of Observational Studies in Epidemiology (STROBE) statement: guidelines for reporting observational studies," PLoS Medicine, vol. 4, p. e296, 2007.

[34] C. Kabali, C. F. von Reyn, D. R. Brooks et al., "Completion of isoniazid preventive therapy and survival in HIV-infected, TST-positive adults in Tanzania," The International Journal of Tuberculosis and Lung Disease, vol. 15, no. 11, pp. 1515-1521, 2011.

[35] S. Charalambous, A. D. Grant, C. Innes et al., "Association of isoniazid preventive therapy with lower early mortality in individuals on antiretroviral therapy in a workplace programme," AIDS, vol. 24, no. 5, pp. S5-S13, 2010.

[36] C. C. Whalen, J. L. Johnson, A. Okwera et al., "A trial of three regimens to prevent tuberculosis in Ugandan adults infected with the human immunodeficiency virus," New England Journal of Medicine, vol. 337, no. 12, pp. 801-807, 1997.

[37] D. M. Gray, T. Young, M. Cotton, and H. Zar, "Impact of tuberculosis preventive therapy on tuberculosis and mortality in HIV-infected children," A Cochrane Review Journal, vol. 4, pp. 1-16, 2009.

[38] H. J. Zar, M. F. Cotton, S. Strauss et al., "Effect of isoniazid prophylaxis on mortality and incidence of tuberculosis in children with HIV: randomised controlled trial," $B M J$, vol. 334, no. 7585, p. 136, 2007.

[39] C. Danel, D. Gabillard, J. Le Carrou et al., "Early ART and IPT in HIV-infected african adults with high CD4 count (temprano trial)," in Proceedings of the Conference on Retroviruses and Opportunistic Infections, vol. 23, pp. 23-26, Seattle, WQ, USA, March 2015.

[40] T. Samandari, T. B. Agizew, S. Nyirenda et al., "6-month versus 36- month isoniazid preventive treatment for tuberculosis in adults with HIV infection in Botswana: a mortality associated with IPT + ART vs. ART alone treatment in PLHIV," Lancet, vol. 377, no. 9777, pp. 1588-1598, 2011.

[41] M. E. Balcells, S. L. Thomas, P. Godfrey-Faussett, and A. D. Grant, "Isoniazid preventive therapy and risk for resistant tuberculosis," Emerging Infectious Diseases, vol. 12, pp. 744-751, 2006.

[42] M. Straetemans, A. L. Bierrenbach, N. Nagelkerke, P. Glaziou, and M. J. van der Werf, "The effect of tuberculosis on mortality in HIV positive people: a meta-analysis," PLoS One, vol. 5, Article ID e15241, 2010.

[43] A. Zumla, P. Malon, J. Henderson, and J. M. Grange, "Impact of HIV infection on tuberculosis," Postgraduate Medical Journal, vol. 76, no. 895, pp. 259-268, 2000.

[44] F. M. Gordin, J. P. Matts, C. Miller et al., "A controlled trial of isoniazid in persons with anergy and human immunodeficiency virus infection who are at high risk for tuberculosis," New England Journal of Medicine, vol. 337, pp. 315-320, 1997.

[45] M. P. Hawken, H. K. Meme, L. C. Elliott et al., "Isoniazid preventive therapy for tuberculosis in HIV-1-infected adults: results of a randomized controlled trial," AIDS, vol. 11, pp. 875-882, 1997.

[46] K. A. Rowe, B. Makhubele, J. R. Hargreaves, J. D. Porter, H. P. Hausler, and P. M. Pronyk, "Adherence to TB preventive therapy for HIV-positive patients in rural South Africa: 
implications for anti-retroviral delivery in resource-poor settings?" International Journal of Tuberculosis and Lung Disease, vol. 9, pp. 263-269, 2005.

[47] A. Rivero, L. López-Cortés, R. Castillo et al., "Randomized clinical trial investigating three chemoprophylaxis regimens for latent tuberculosis infection in HIV-infected patients," Enferm Infecc Microbiol Clin, vol. 25, no. 5, pp. 305-310, 2007.

[48] J. L. Casado, S. Moreno, J. Fortún et al., "Risk factors for development of tuberculosis after isoniazid chemoprophylaxis in human immunodeficiency virus-infected patients," Clinical Infectious Diseases, vol. 34, no. 3, pp. 386-389, 2002.

[49] J. W. Pape, S. S. Jean, J. L. Ho, A. Hafner, and W. D. Johnson Jr., "Effect of isoniazid prophylaxis on incidence of active tuberculosis and progression of HIV infection," Lancet, vol. 342, no. 8866, pp. 268-272, 1993.

[50] H. C. Bucher, L. E. Griffith, G. H. Guyatt et al., "Isoniazid prophylaxis for tuberculosis in HIV infection: a meta-analysis of randomized controlled trials," AIDS, vol. 13, no. 4, pp. 501-507, 1999.

[51] N. A. Halsey, J. S. Coberly, J. Desormeaux et al., "Randomised trial of isoniazid versus rifampicin and pyrazinamide for prevention of tuberculosis in HIV-1 infection," Lancet, vol. 51, no. 9105, pp. 786-792, 1998.

[52] D. Wilkinson, S. B. Squire, and P. Garner, "Effect of preventive treatment for tuberculosis in adultsinfected with HIV: systematic review of randomised placebo controlled trials," BMJ, vol. 317, pp. 625-629, 1998.

[53] A. Mwinga, M. Hosp, P. Godfrey-Faussett et al., "Twice weekly tuberculosis preventive therapy in HIV infection in Zambia," AIDS, vol. 12, no. 19, pp. 2447-2457, 1998.

[54] J. L. Johnson, A. Okwera, D. L. Hom et al., "Duration of efficacy of treatment of latent tuberculosis infection in HIVinfected adults," AIDS, vol. 15, no. 16, pp. 2137-2147, 2001.

[55] N. A. Martinson, G. L. Barnes, L. H. Moulton et al., "New regimens to prevent tuberculosis in adults with HIV infection," The New England Journal of Medicine, vol. 365, no. 1, pp. 11-20, 2011.

[56] G. J. Churchyard, K. L. Fielding, J. J. Lewis et al., "A trial of mass isoniazid preventive therapy for tuberculosis control," New England Journal of Medicine, vol. 370, no. 4, pp. 301-310, 2014.

[57] M. X. Rangaka, R. J. Wilkinson, A. Boulle et al., "Isoniazid plus antiretroviraltherapy to prevent tuberculosis: a randomized double-blind placebocontrolled trial," Lancet, vol. 384, pp. 682-690, 2014.

[58] R. Kamath, V. Sharma, S. Pattanshetty, M. B. Hegde, and V. Chandrasekaran, "HIV-TB coinfection: clinico-epidemiological determinants at an antiretroviral therapy center in Southern India," Lung India, vol. 30, no. 4, pp. 302-306, 2013.

[59] A. Belay, Z. Alamrew, Y. Berie, B. Tegegne, G. Tiruneh, and A. Feleke, "Magnitude and correlates of tuberculosis among HIV patients at felege hiwot referral hospital, bahir dar city, northwest Ethiopia," Journal of Clinical Medicine Research, vol. 2, no. 4, pp. 77-83, 2013.

[60] M. F. Franke, J. M. Robins, J. Mugabo et al., "Effectiveness of early antiretroviral therapy initiation to improve survival among HIV-infected adults with tuberculosis: a retrospective cohort study," PLoS Medicine, vol. 8, no. 5, Article ID e1001029, 2011. 


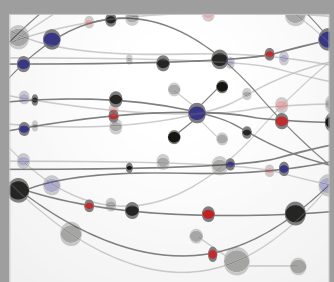

The Scientific World Journal
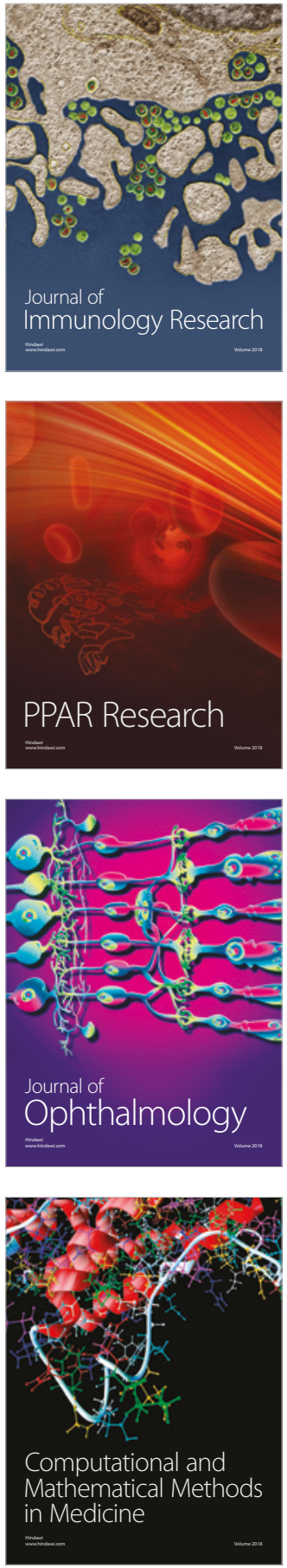

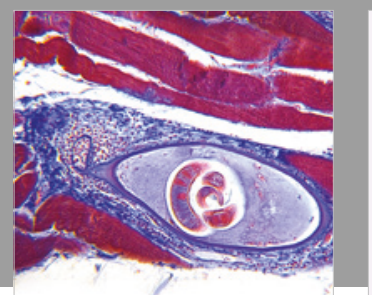

Gastroenterology Research and Practice

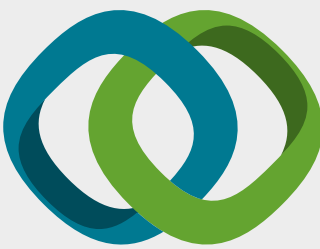

\section{Hindawi}

Submit your manuscripts at

www.hindawi.com
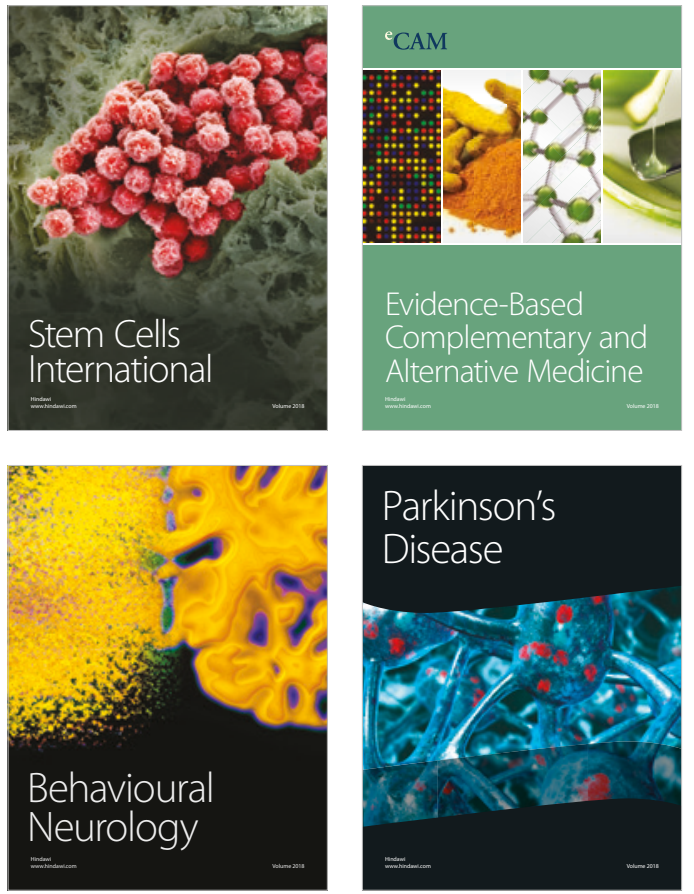

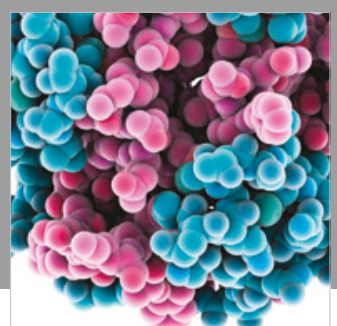

ournal of

Diabetes Research

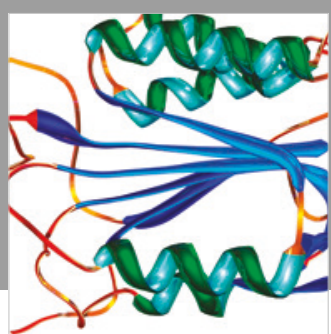

Disease Markers
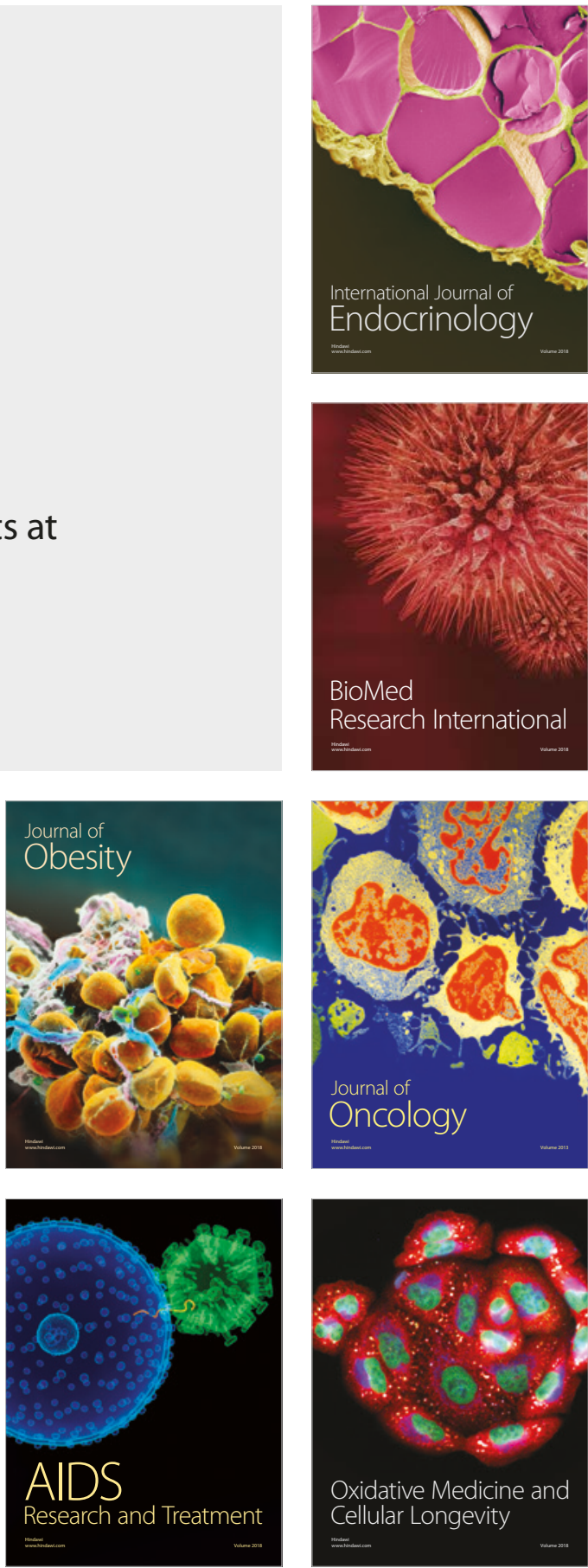